\title{
Review of magnetic resonance imaging features of complications after anterior cruciate ligament reconstruction
}

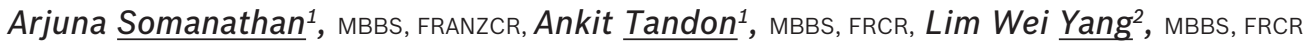

\begin{abstract}
The anterior cruciate ligament $(A C L)$ is an important stabiliser of the knee and is commonly torn in sports injuries. Common indications for imaging after $\mathrm{ACL}$ reconstruction include persistent symptoms, limitation of motion and re-injury. Important postoperative complications include graft failure, impingement, arthrofibrosis and graft degeneration. This article aimed to familiarise the radiologist with magnetic resonance (MR) imaging appearances of properly positioned intact $\mathrm{ACL}$ grafts and to provide a comprehensive review of MR imaging features of complications following $\mathrm{ACL}$ reconstruction.
\end{abstract}

Keywords: ACL, complications, knee, MR imaging, postoperative

\section{SURGICAL ASPECTS OF ACL RECONSTRUCTION}

The goal of anterior cruciate ligament $(\mathrm{ACL})$ reconstruction is to restore knee function that is identical to that of the native ligament and prevent long-term irreversible damage. $\mathrm{ACL}$ reconstruction remains the gold standard of care, particularly in active patients in whom non-operative management has been shown to result in poorer functional outcome. ${ }^{(1)}$ The timing of surgery and type of graft utilised continue to be the subject of debate. For most patients, early reconstruction (within 21 days) is preferred over delayed surgery. ${ }^{(2)}$

\section{Graft types}

Autografts are considered the gold standard. Allograft constructs are occasionally used, but they are comparatively more prone to mechanical failure and are associated with increased synovitis and osteolysis. ${ }^{(3)}$ The two autografts commonly used for ACL reconstruction are patellar tendon and hamstring grafts.

\section{Patellar tendon graft}

Patellar tendon grafts (Fig. 1) are harvested from the central third of the patellar tendon. They are $50 \%$ stronger than the native $\mathrm{ACL}$ and are thus an ideal graft. Bone plugs taken from the patella and tibial tubercle have the advantage of bone-to-bone healing of the graft when compared to hamstring grafts. Other advantages include increased strength, decreased rate of re-tear and increased knee stability. Complications from the donor site include patellar fracture, tendinitis and tendon rupture, patellofemoral pain and quadriceps weakness.

\section{Hamstring tendon graft}

Hamstring grafts (Fig. 2) are classified into semitendinosus only, and combined semitendinosus and gracilis grafts. Hamstring tendon grafts require a smaller incision and graft site

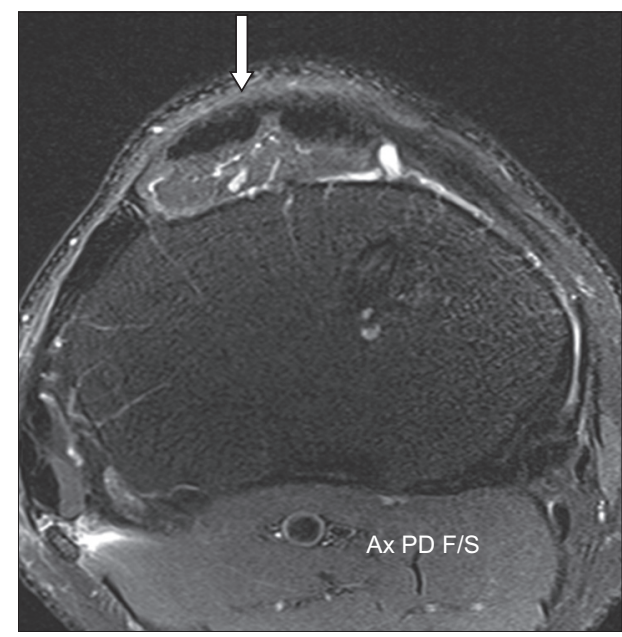

Fig. 1 Axial proton density fat-saturated MR image following anterior cruciate ligament reconstruction using a patellar tendon graft shows scarring (arrow) in the central third of the patellar tendon, where the graft was harvested.

complications are rare, in particular in comparison to patellar tendon grafts, both of which are advantages over patellar tendon grafts. With hamstring grafts, the tendons regenerate earlier and usually demonstrate a normal appearance by a year.

\section{Optimal graft placement}

The current surgical practice is to place the femoral tunnel within the femoral footprint of the native ACL. ${ }^{(2)}$ In order to achieve optimal function, the femoral tunnel should not be placed anterior to the lateral intercondylar ridge, an anatomical landmark that can be found during surgery. ${ }^{(2)}$

The ideal tibial insertion site of the graft is the posterior aspect of the tibial footprint, located close to where the posterolateral band of the native ACL would be inserted. A tunnel placed too anteriorly predisposes the graft to impingement against the roof of the intercondylar notch during extension. ${ }^{(4)}$ 

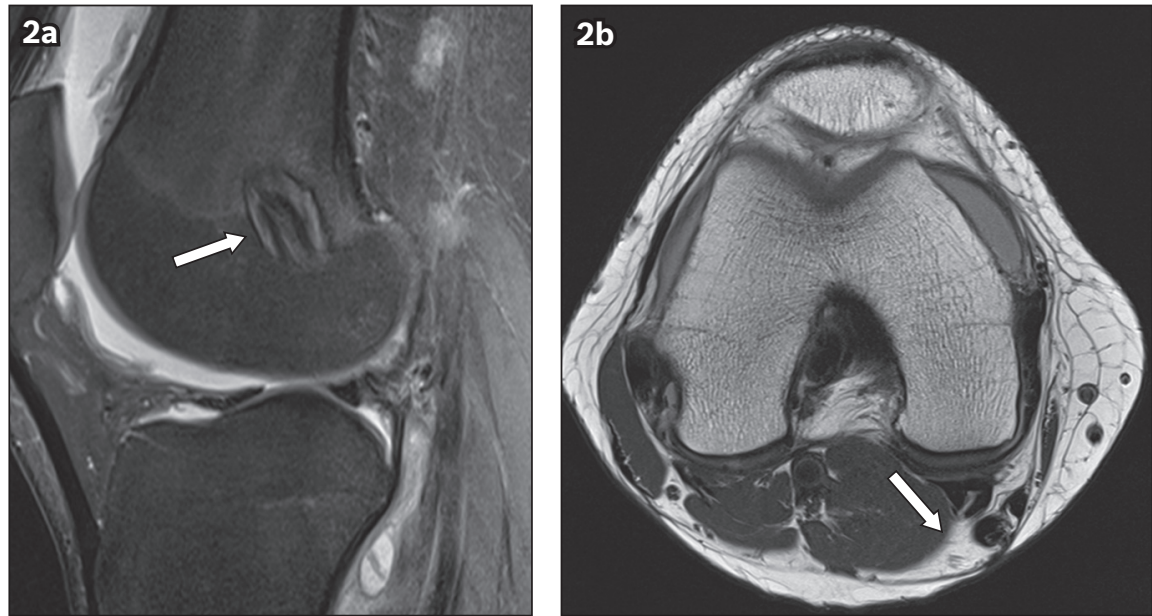

Fig. 2 A patient with anterior cruciate ligament reconstruction using a hamstring graft. (a) Sagittal proton density (PD) fat-saturated MR image shows a looped appearance of the grafts (arrow) within the femoral tunnel, differentiating them from patellar grafts. (b) Axial PD MR image shows the regenerated tendons (arrow) one year post surgery. Regeneration makes identification of prior graft harvesting difficult.
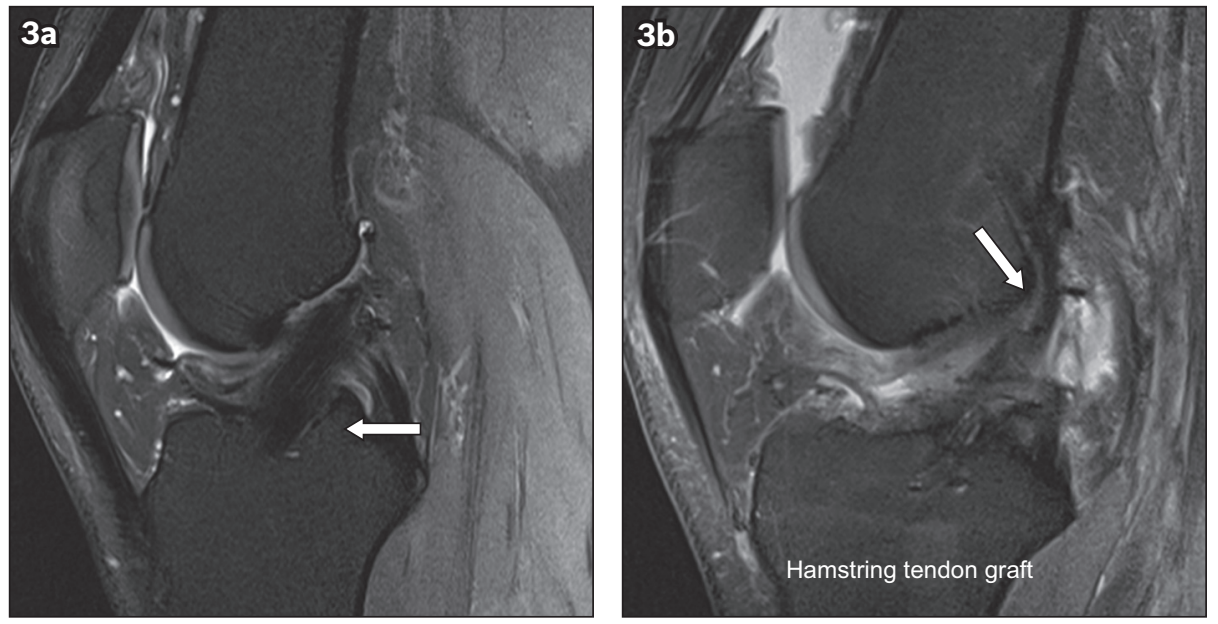

Fig. 3 Sagittal proton density fat-saturated MR images show (a) the homogeneous low signal of a patellar tendon graft (arrow) and (b) normal linear striations (arrow) of separate bundles in the hamstring graft.

\section{MR APPEARANCES OF NORMAL ACL GRAFTS}

In the first three months following $A C L$ surgery, the grafts are avascular and demonstrate a similar magnetic resonance (MR) signal to the native harvest site (Fig. 3). From four to eight months, the grafts undergo revascularisation and have an intermediate signal. After 12 months, the grafts undergo 'ligamentisation', resulting in a signal similar to the native $A C L$, although this can sometimes take up to 24 months.

\section{Optimal femoral tunnel position}

The optimal position of the femoral tunnel is along the posterior femoral intercondylar notch, immediately at the intersection of the posterior femoral cortex and the posterior physeal scar (Fig. 4). An overly anterior position of the femoral tunnel can lead to knee instability.

\section{Optimal tibial tunnel position}

The tibial tunnel is optimally positioned when the anterior margin of the tunnel lies just posterior to the roof of the intercondylar notch, as represented by Blumensaat's line (Fig. 5). Positioning the tibial tunnel too anteriorly can lead to graft impingement and placing it too far posteriorly can lead to instability.

\section{POSTOPERATIVE COMPLICATIONS}

Complications following $\mathrm{ACL}$ reconstruction can be broadly categorised into two groups based on the presenting symptoms (Box 1). The causes of a lax and unstable knee include graft disruption secondary to graft tear, and lysis and expansion of the graft tunnel, which may be due to granulation tissue or ganglion cyst formation. The second major group of symptoms that patients may encounter following ACL reconstruction is decreased range of motion, which can be a result of graft impingement and localised or diffuse arthrofibrosis.

\section{Graft disruption}

Complete and partial tears of $\mathrm{ACL}$ grafts can result in lax and unstable knees. Disruption of the posterolateral bundle is more common than that of the anteromedial bundle. A study by Amin et $\mathrm{al}^{(5)}$ demonstrated partial tears of the posterolateral bundle in $27 \%$ of post-ACL knees and complete tears in $24 \%$ of them. The MR appearances of a complete tear of an $\mathrm{ACL}$ graft is similar to 
that of a complete tear of a native $\mathrm{ACL}$, with abnormal orientation of the fibres and complete discontinuity (Fig. 6). Partial tears demonstrate discontinuity of fibres (Fig. 7).

The ACL graft, particularly the patellar bone tendon graft, often shows an intermediate signal for up to two years post surgery, and this should not be mistaken for a tear. In such cases, the fibres remain intact, unlike in a partial tear.

\section{ACL graft ganglion}

Ganglions may form along ACL grafts and, if large enough, may lead to expansion or even lysis of the femoral or tibial tunnel and consequently pain and/or instability of the knee (Fig. 8). In particular, extrusion of the ganglion into the intercondylar notch can result in pain, limited range of motion and knee locking, while extrusion into the non-articular opening can present as a palpable mass.

\section{Graft impingement}

If the tibial tunnel is placed too far anteriorly, it leads to chronic mechanical stress and impingement of the graft, which in turn leads to degeneration and tear. Intercondylar roof impingement usually affects the anterior surface of the graft before extension

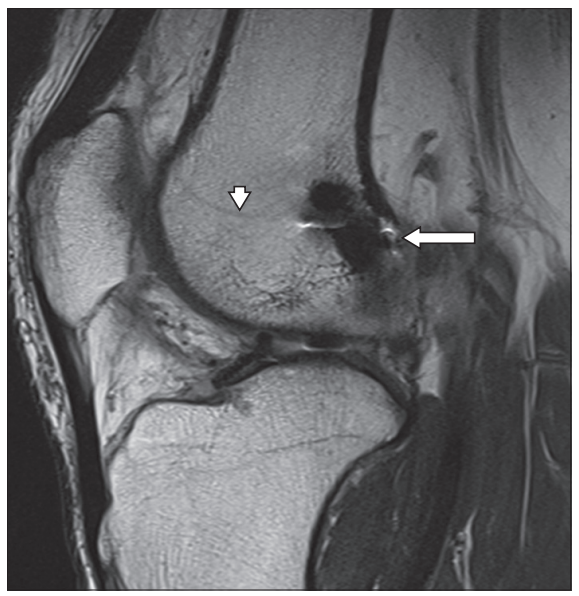

Fig. 4 Sagittal proton density MR image shows a satisfactory femoral tunnel (arrow) at the intersection of the posterior femoral cortex and the posterior physeal scar (arrowhead).
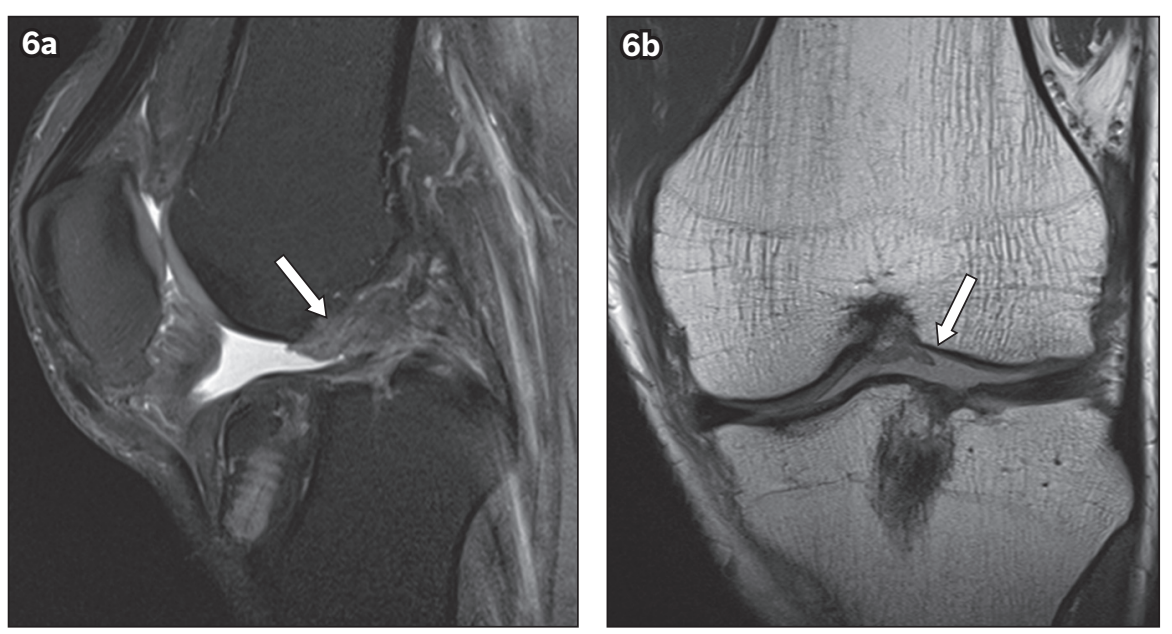

Fig. 6 (a) Sagittal proton density (PD) fat-saturated and (b) coronal PD MR images show complete loss of continuity of the anterior cruciate ligament (ACL) graft fibres with a remnant graft stump (arrows in $\mathrm{a} \& \mathrm{~b}$ ). Complete graft rupture was confirmed on arthroscopy and the patient underwent ACL revision surgery. to involve the posterior fibres. Another cause of impingement is osseous spurs in the intercondylar notch (Fig. 9).

\section{Arthrofibrosis}

Arthrofibrosis refers to scar tissue within the knee and is a common cause of decreased range of motion of the knee following ACL reconstruction. It can either be diffuse, involving multiple compartments of the knee (Fig. 10), or more commonly present as a localised nodular fibrous tissue forming anterior to the distal

\begin{tabular}{|c|c|}
\hline \multicolumn{2}{|c|}{$\begin{array}{l}\text { Box 1. Potential complications post anterior cruciate ligament } \\
\text { reconstruction and associated symptoms: }\end{array}$} \\
\hline Symptoms & Possible causes \\
\hline Lax and unstable knee & $\begin{array}{l}\text { - Graft disruption } \\
\text { - Partial and complete tears } \\
\text { - Ganglion cyst formation }\end{array}$ \\
\hline Decreased range of motion & $\begin{array}{l}\text { - Graft impingement } \\
\text { - Graft tunnel placement } \\
\text { - Intercondylar notch bony spurs } \\
\text { - Arthrofibrosis } \\
\text { - Diffuse } \\
\text { - Localised (cyclops lesion) }\end{array}$ \\
\hline
\end{tabular}

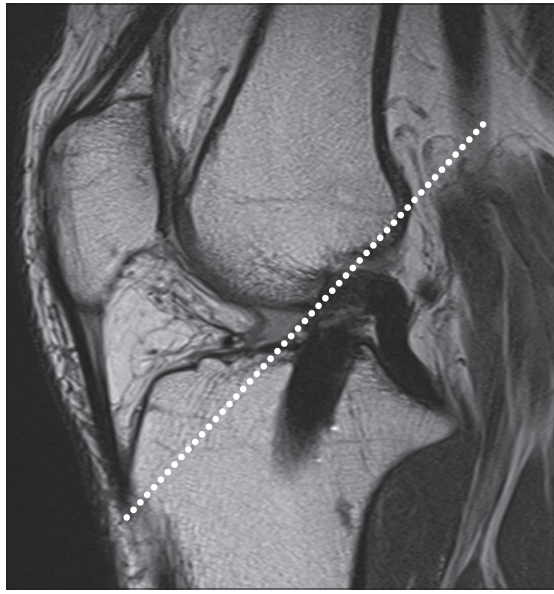

Fig. 5 Sagittal proton density MR image shows a Blumensaat's line (dotted line), which parallels the roof of the intercondylar notch. A satisfactory tibial tunnel is also seen posterior to the Blumensaat's line. 

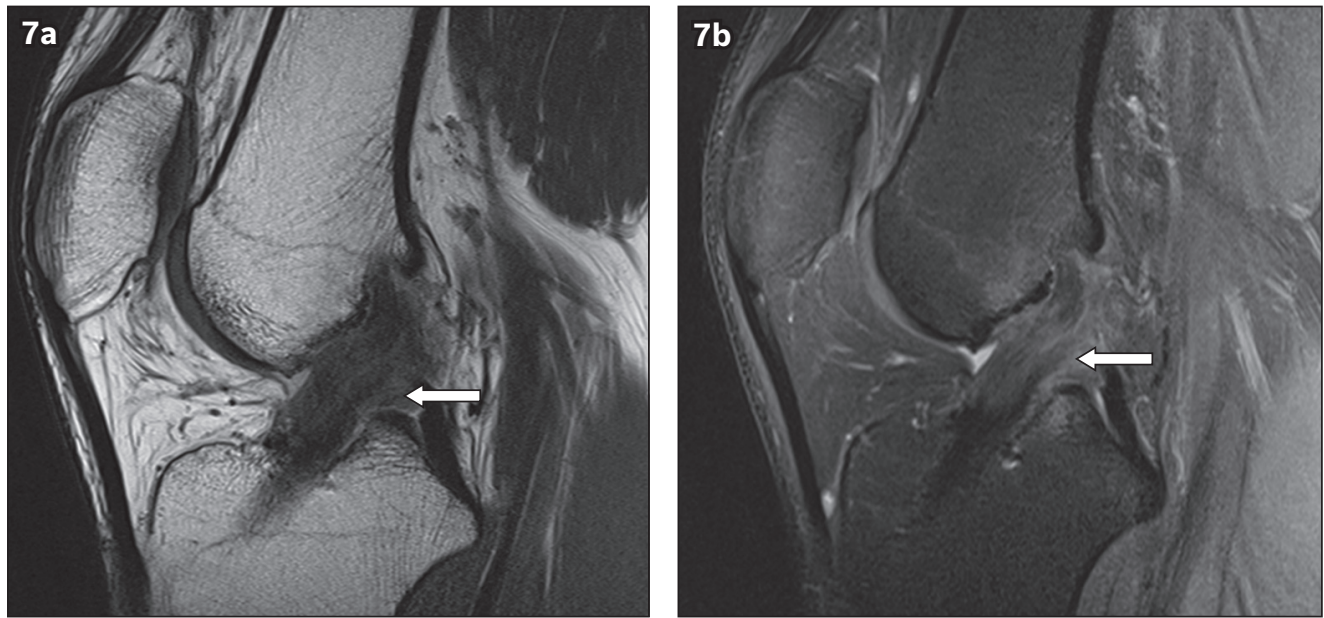

Fig. 7 (a) Sagittal proton density and (b) T2-W fat-saturated MR images show a partial tear with discontinuity and increased signal (arrows in a \& b) in the anterior cruciate ligament graft.
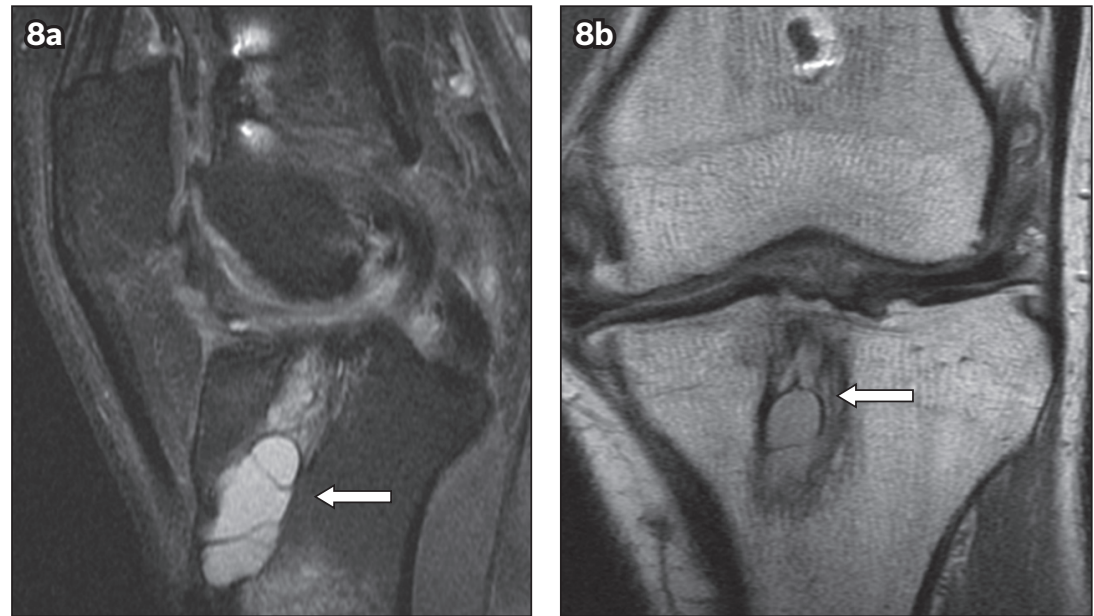

Fig. 8 (a) Sagittal proton density (PD) fat-saturated and (b) coronal PD MR images show a lobulated septated cystic lesion (arrows in a \& b) within the tibial tunnel. Tunnel expansion is seen.
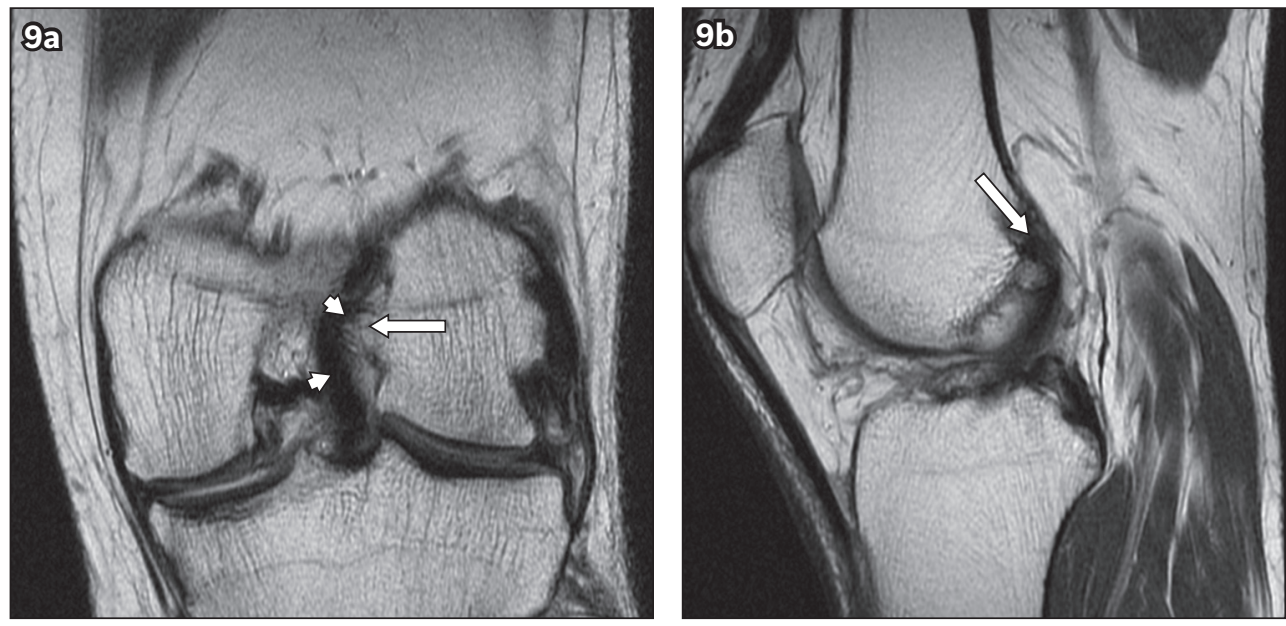

Fig. 9 (a) Coronal proton density (PD) and (b) sagittal PD MR images show an osseous spur (arrows in a \& b) arising from the medial aspect of the lateral femoral condyle, causing bowing of the anterior cruciate ligament graft (arrowheads), although no abnormal graft signal is shown.

ACL graft, known as a cyclops lesion (Figs. 10 \& 11). The cyclops lesion protrudes between the femur and the tibia at the anterior aspect of the intercondylar notch, superior to where the graft enters the tibial tunnel. ${ }^{(6)}$

Cyclops lesions are seen in approximately $1 \%-10 \%$ of post-ACL reconstruction patients. ${ }^{(7)}$ The key finding is soft tissue thickening anterior to the distal $\mathrm{ACL}$, usually seen as low to intermediate signal on T1-weighted and T2-weighted MR imaging.

\section{Donor site complications}

Donor site complications are more common with patellar tendon grafts and include fractures of the patella, and partial or complete 

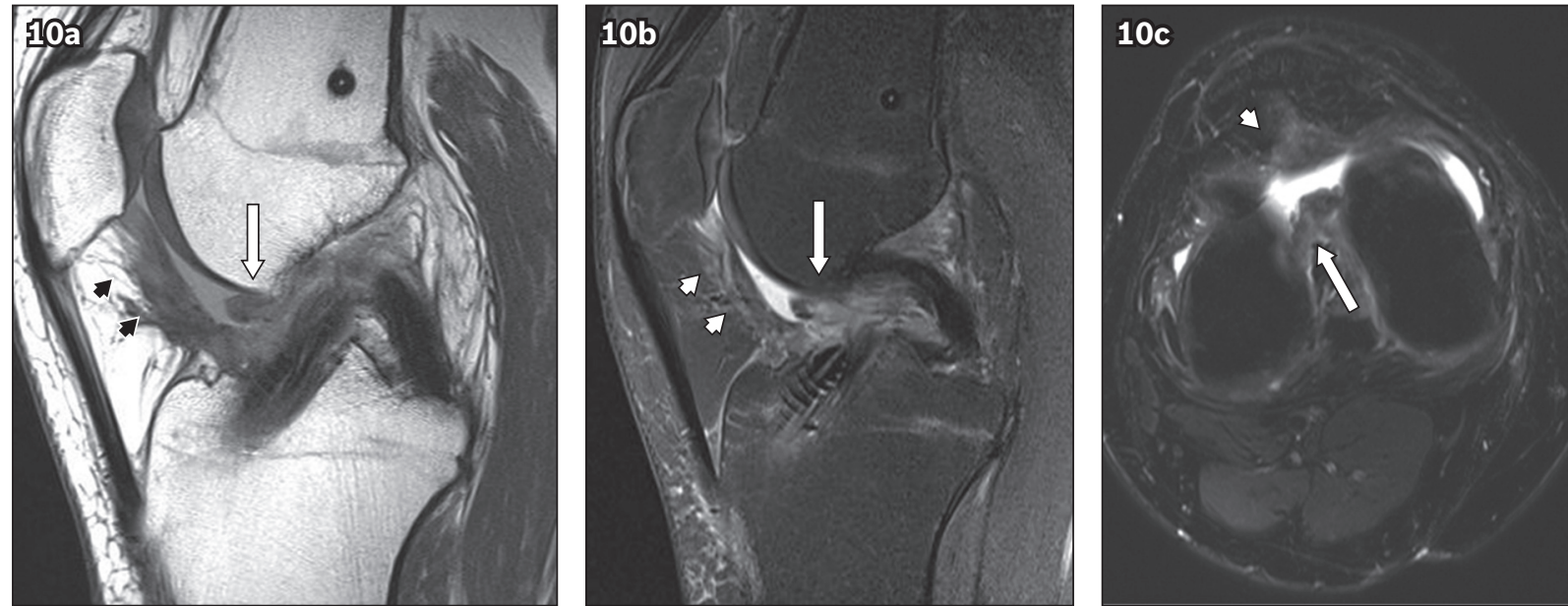

Fig. 10 (a) Sagittal proton density, (b) Sagittal T2-W and (c) axial gradient-recalled echo MR images show both forms of arthrofibrosis. A spiculated area of low signal intensity within the Hoffa's fat pad represents diffuse arthrofibrosis (arrowheads in a-c). A cyclops lesion (arrows in a-c) is also present.
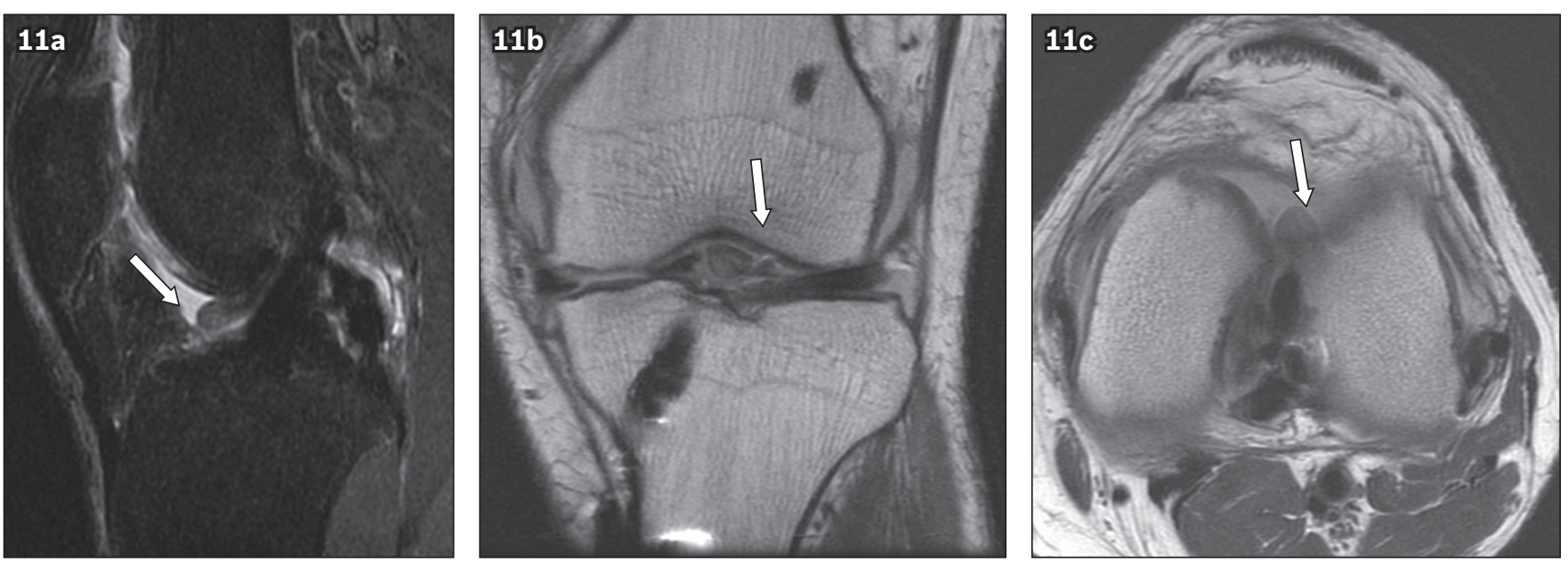

Fig. 11 (a) Sagittal proton density (PD) fat-saturated, (b) coronal PD and (c) axial PD MR images show a focal nodular low signal area anterior to the intra-articular portion of the anterior cruciate ligament graft, in keeping with a cyclops lesion (arrows in a-c).

tears of the patellar tendon, bursitis and haematoma. ${ }^{(8)}$ Following harvesting, it is normal to see tendon thickening and a central gap within the patellar tendon corresponding to the site of tendon harvesting, which usually fills in with reparative tissue by two years. ${ }^{(9)}$ Donor site complications of hamstring tendon grafts are relatively rare, with the most common complication being a fluid collection at the donor site.

\section{CONCLUSION}

Postoperative complications can be evaluated accurately with MR imaging. Eliciting a clinical history of either an unstable knee or loss of normal range of motion is helpful in the assessment of associated complications. Knowing the normal appearance of the ACL graft and its changes over time can help to avoid potential pitfalls in imaging interpretation.

\section{REFERENCES}

1. Paschos NK, Howell SM. Anterior cruciate ligament reconstruction: principles of treatment. EFORT Open Rev 2016; 1:398-408.

2. Nandra R, Matharu GS, Porter K, Ashraf T, Greaves I. A review of anterior cruciate ligament injuries and reconstructive techniques. Part 2: Treatment. Trauma 2013; 15:116-27.

3. Mascarenhas R, MacDonald PB. Anterior cruciate ligament reconstruction: a look at prosthetics--past, present and possible future. Mcgill I Med 2008; 11:29-37.

4. Nandra R, Najran P, Matharu GS, et al. A review of anterior cruciate ligament injuries and reconstructive techniques. Part 1: Basic science. Trauma 2013; 15:107-15.

5. Amin MF, Abd El Kareem H, Sadek AF, Saleh AN. MRI evaluation of the knee post double bundle ACL reconstruction: association of graft findings and comparison with arthroscopy. Egypt J Radiol Nucl Med 2016; 47:521-9.

6. Shelbourne KD, Wilckens JH, Mollabashy A, DeCarlo M. Arthrofibrosis in acute anterior cruciate ligament reconstruction. The effect of timing of reconstruction and rehabilitation. Am J Sports Med 1991; 19:332-6.

7. Bencardino JT, Beltran J, Feldman MI, Rose DJ. MR imaging of complications of anterior cruciate ligament graft reconstruction. Radiographics 2009; 29:2115-26.

8. Grassi A, Bailey JR, Signorelli $\mathrm{C}$, et al. Magnetic resonance imaging after anterior cruciate ligament reconstruction: a practical guide. World J Orthop 2016; 7:638-49.

9. Saifuddin A, Tyler P, Hargunani R. Musculoskeletal MRI. 2nd ed. CRC Press, 2016. 


\section{SINGAPORE MEDICAL COUNCIL CATEGORY 3B CME PROGRAMME} (Code SMJ 201902B)

Question 1. Regarding anterior cruciate ligament (ACL) graft types:

(a) Allografts are the gold standard.

(b) Patellar tendon grafts are stronger than hamstring tendon grafts.

(c) Hamstring grafts have more graft site complications.

(d) Patellar tendon grafts are less likely to re-tear.

Question 2. Regarding graft placement:

(a) The femoral tunnel should be anterior to the lateral intercondylar ridge.

(b) The intercondylar ridge can be seen during surgery.

(c) The tibial tunnel should be placed along the posterior aspect of the tibial footprint.

(d) Impingement may occur if the tibial tunnel is too anterior.

Question 3. Regarding graft disruption:

(a) The anteromedial bundle is more commonly torn.

(b) Intermediate signal in the ACL graft can be seen in intact grafts one year after surgery.

(c) The best clue for partial re-tear of grafts is fibre discontinuity.

(d) It can present with similar MR signs to disruption of the native ACL.

Question 4. With regard to arthrofibrosis:

(a) There are three forms.

(b) The localised form is more common.

(c) The localised form (i.e. cyclops lesion) is usually posterior to the distal ACL attachment.

(d) It is usually seen as low to intermediate signal on T1- and T2-weighted MR imaging.

Question 5. With regard to ACL graft complications:

(a) Ganglions can present as a palpable mass.

(b) Intercondylar roof impingement usually affects the posterior fibres of the graft first.

(c) Osseous spurs usually cause instability.

(d) Graft tear may occur if the tibial tunnel is too anterior.

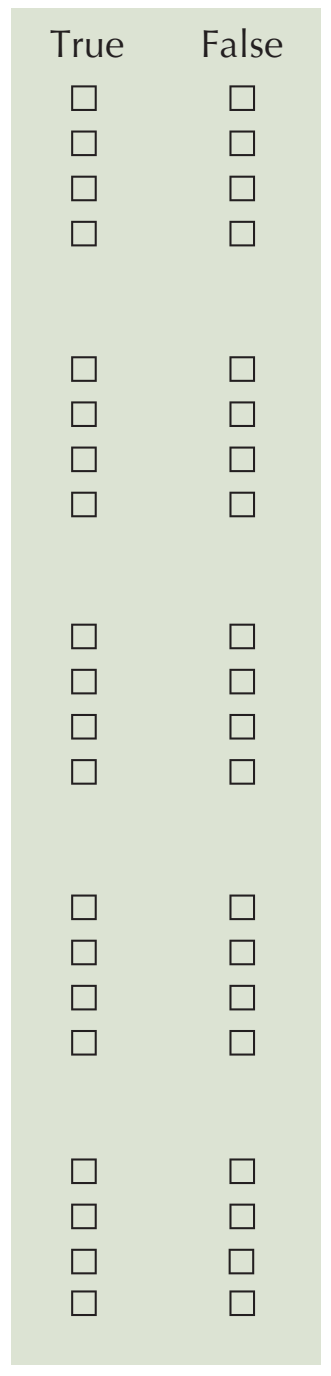

\section{Doctor's particulars:}

Name in full:

Specialty:

MCR no.:

Email:

\section{SUBMISSION INSTRUCTIONS:}

Visit the SMJ website: http://www.smj.org.sg/current-issue and select the appropriate quiz. You will be redirected to the SMA login page.

For SMA member: (1) Log in with your username and password (if you do not know your password, please click on 'Forgot your password?'). (2) Select your answers for each quiz and click 'Submit'.

For non-SMA member: (1) Create an SMJ CME account, or log in with your SMJ CME username and password (for returning users). (2) Make payment of SGD 21.40 (inclusive of $7 \%$ GST) via PayPal to access this month's quizzes. (3) Select your answers for each quiz and click 'Submit'.

\section{RESULTS:}

(1) Answers will be published online in the SMJ April 2019 issue. (2) The MCR numbers of successful candidates will be posted online at the SMJ website by 15 April 2019. (3) Passing mark is $60 \%$. No mark will be deducted for incorrect answers. (4) The SMJ editorial office will submit the list of successful candidates to the Singapore Medical Council. (5) One CME point is awarded for successful candidates. (6) SMC credits CME points according to the month of publication of the CME article (i.e. points awarded for a quiz published in the December 2017 issue will be credited for the month of December 2017, even if the deadline is in January 2018).

Deadline for submission: (February 2019 SMJ 3B CME programme): 12 noon, 7 April 2019. 